\title{
Olesya Khanina* and Andrey Shluinsky* Intransitive verbs in Enets: A contribution to the typology of split intransitivity
}

https://doi.org/10.1515/zfs-2019-0001

\begin{abstract}
This paper contributes to the typology of "active-stative" split intransitivity and middle voice with a detailed case study: it proceeds from a typological comparison of the two phenomena, which are usually treated apart, to an analysis of the Enets data and a discussion of its place in the typology of possible intransitive splits. Enets (Uralic, Samoyedic) has two classes of intransitive verbs, and each class uses its own cross-reference paradigm in all finite forms. The paper provides an account of the morphology of this intransitive split and its connection to the lexical aspect, followed by an overview of semantic composition of the two lexical classes; special attention is given to cases of class variation available for a dozen verbs. The research is based on the data of a fieldworkers' corpus and thus also shows the advantages of a corpus-based approach to this phenomenon.
\end{abstract}

Keywords: intransitive verbs, split intransitivity, active alignment, middle voice, Enets, Samoyedic, corpus-based grammatical descriptions

\section{Introduction}

\subsection{The phenomenon}

This paper is a study of two classes of intransitive verbs in a Northern Samoyedic (< Uralic) language of northern Siberia, Enets. Enets has two classes of intransitive verbs defined by a series of cross-reference markers that the verbs take for indexing the person and number of the subject. Some intransitive verbs (henceforth subjective verbs) take "subjective cross-reference series", which is also used for indexing person and number of the subjects of transitive verbs. The other intransitive verbs (henceforth middle verbs) take "middle cross-reference series" attested exclusively with this class. Examples (1)-(2) illustrate the phenomenon: the 1sG subject cross-reference marker $-z$ ? used in (1) belongs to the "subjective" cross-

\footnotetext{
*Corresponding authors: Olesya Khanina, Andrey Shluinsky, Institute of Linguistics, Russian Academy of Sciences, Moscow, Russia, e-mails: olesya.khanina@gmail.com, ashl@yandex.ru
} 
reference paradigm, while the 1SG subject cross-reference marker -j? used in (2) belongs to the "middle"1 cross-reference paradigm.

$$
\begin{aligned}
& \text { tJz } t \int i k o z \quad t f i \text { potabu-d } \quad \text { kan'e-z? } \\
& \text { so this.ABL.SG here Potapovo-DAT.SG leave.PFV-1SG.S } \\
& \text { 'So after that I went to Potapovo.' }
\end{aligned}
$$

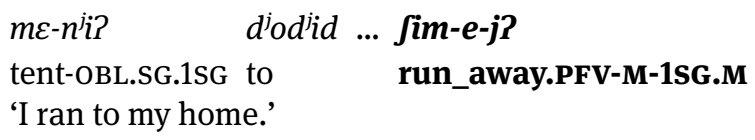

All Northern Samoyedic languages have the two inflectional patterns available for intransitive verbs. The distribution between the two patterns is lexical, and it is mostly exclusive, though a small number of verbs can be used with either inflectional pattern.

Grammatical descriptions of FE (Sorokina 2010 and Siegl 2013) say quite little about the two Enets intransitive paradigms, apart from stating the mere fact of their existence and presenting the lists of affixes. For details of the intransitive split in other Northern Samoyedic languages, see Salminen (1997: 95-96), Khanina (2008), Nikolaeva (2014: 78-79), Tatevosov (2016) for Tundra Nenets, Verbov (1975: 90-92) for Forest Nenets, and Tereščenko (1979: 183-196) for Nganasan. Diachronically, the Northern Samoyedic middle paradigm is supposed to be based on a combination of a historic middle marker with the simpler subjective paradigm (Mikola 2004: 124-127).

Enets, together with the other Northern Samoyedic languages, also has derivational viewpoint aspect, as well as extensive aspectual and some valencychanging derivations, so the intransitive split is one more dimension in which the Enets verbal lexicon is structured.

\subsection{Typology of split intransitivity}

The descriptive goal of this paper is to analyze the two Enets classes and to investigate factors that influence the membership in the subjective vs. middle class for an intransitive verb. However, this paper also has a typological dimension. We point to the similarity of two linguistic phenomena usually analyzed separately, and suggest using the Enets data to analyze the difference between semantic pre-

1 Or "reflexive" paradigm in the traditional Samoyedic terminology.

2 FE refers to the Forest dialect of Enets, more information on the Enets dialects is given in Section 2. 
dictions made for each of them. Namely, we mean two types of split intransitivity: active alignment vs. middle marking; details for each of them are given below.

There are a number of cross-linguistic studies of the so-called split intransitivity, split S, or active alignment (cf. among others Klimov 1974; Dixon 1979; Merlan 1985; Lazard 1986; Mithun 1991; Kibrik 1997). The notion of split intransitivity is used in them narrowly to refer to a phenomenon of intransitive verbs being split into two classes: into "subjective" verbs that take the same cross-reference markers for their subjects as transitive verbs do for their subjects, and into "objective" verbs that take the same cross-reference markers for their subjects as transitive verbs do for their objects. Even though Merlan's definition of split intransitivity is broader: "different inflectional patterns within the larger class of intransitive verbs" (Merlan 1985: 324), the Enets phenomenon discussed in this paper is not in the scope of her study, nor is it in the scope of most other studies of split intransitivity in this understanding. To the best of our knowledge, Gianollo (2005) dealing with Latin deponent verbs and Khanina (2008) dealing with intransitive verbs in Nenets (a language closely related to Enets) are the only studies that actually use the term "split intransitivity" broadly: for a morphological split within intransitive verbs with no correlation to marking of transitive objects. ${ }^{3}$

Another typological phenomenon that also deals with a split in intransitive verbs of a language is middle voice: this notion goes back to classical IndoEuropean studies and was applied to other languages in the context of crosslinguistic comparison by Givón (1981), Shibatani (1985), and particularly, Kemmer (1993), cf. also an overview in Kazenin (2001). Following Lyons (1968: 373) for Greek, Kemmer (1993: 1) informally defines the middle voice as indicating that “the 'action' or 'state' affects the subject of the verb or his interests”. In her study, Kemmer analyzes a large sample of languages with middle markers, and noteworthy, most of these markers are separate affixes and not series of cross-reference markers. So far very few languages with a Greek-like dedicated middle cross-reference paradigm have been discussed in the typological literature: in fact, except for classical Indo-European, it is only Fula (< Atlantic) with its middle paradigm (Koval and Gnalibouly 1997; Kaufmann 2007, among others). ${ }^{4}$ Samoyedic languages are well known in Uralic studies for their middle

3 Sometimes the term "split intransitivity" is also used in a different broad sense for phenomena also known as unaccusativity vs. unergativity distinction, cf. Van Valin (1990); Arkadiev (2008). 4 There are indeed more languages with dedicated middle cross-reference paradigms, but they are not usually referred to in the context of this typological discussion. E. g. Hungarian so-called $i k$-verbs having a special cross-reference paradigm in singular (see e. g. Rounds 2001: 16-20) may be described as middle verbs. It is noteworthy that the Hungarian middle paradigm is cognate to the Samoyedic middle paradigm discussed in this paper for Enets; see Helimski (1982: 70-88). 
cross-reference series (e.g. Tereščenko 1967; Helimski 1982: 76-81; Janhunen 1998; Mikola 2004: 124-127), but the Samoyedic data have never been discussed in detail in the context of typology of middle voice. Looking at it from a terminological point of view, it is only a dedicated paradigm for "middle" verbs and not just an affix for "middle" that produces an intransitive split in a language, so languages with a middle affix do not provide examples of split intransitivity, unlike languages with middle paradigms.

There is an evident similarity between the two ways languages can use to split their intransitive verbs into two classes: either by using active alignment, or by using a dedicated "middle” paradigm. Klaiman (1991:108) suggested a schematic representation of the similarity, reproduced in Table 1 in a slightly modified way: $\mathrm{A}$ and $\mathrm{P}$ stand here for agent-like and patient-like arguments of a transitive verb, S stands for the sole core argument of an intransitive verb, Sa, Sp and Sm illustrate the alignment of subjective, objective, and middle intransitive verbs, correspondingly; sharing a cell refers to being encoded by one morphological object.

Table 1: Comparison of the two ways languages can use to split their intransitive verbs: active alignment vs. a dedicated paradigm for “middle” verbs.

\begin{tabular}{|l|l|l|}
\hline \multicolumn{2}{|l|}{ Active alignment: subjective vs. objective } \\
\hline transitive & $\mathrm{A}$ & $\mathrm{P}$ \\
\cline { 1 - 1 } intransitive & $\mathrm{Sa}$ & $\mathrm{Sp}$ \\
\hline Middle voice marked by dedicated paradigm: & subjective vs. middle \\
\hline transitive & $\mathrm{A}$ & $\mathrm{P}$ \\
intransitive & $\mathrm{Sa}$ & $\mathrm{Sm}$ \\
\hline
\end{tabular}

Morphologically, these two systems are clearly different, but in both cases we ultimately deal with a split in the alignment of intransitive verbs. The question arises if these two types have common semantic features.

One of Merlan's (1985) findings consisted in the fact that in split intransitivity systems distinguishing subjective vs. objective intransitive verbs, one of the two intransitive classes would always be more numerous and default-like, while the other one would be less numerous and distributionally limited. This special, less numerous class can be subjective in some languages, and objective in other languages, but importantly there is a set of lexical meanings that cross-linguistically tend to belong to the special class, regardless of whether it is actually subjective or objective in a given language. These meanings are those relating to bodily functions and processes. If the special class is indeed very small (Merlan calls it a "minimal intransitive subclass"), then it will almost unexceptionally consist of 
such verbs relating to bodily functions and processes, though a part of such verbs may belong to the bigger class as well (Merlan 1985: 347).

It has never been investigated whether split intransitivity systems distinguishing subjective vs. middle verbs follow this cross-linguistic trend, i. e. whether their less numerous class, which is presumably always middle in these systems, tends to contain the set of verbal meanings discovered by Merlan (1985) as typical for a less numerous class in systems opposing subjective vs. objective verbs. In the present paper, we check this for Enets, and by doing this we make the first step in building a typology of the possible semantic organization of split intransitivity systems regardless of their morphological organization.

\subsection{Structure of the paper}

The rest of the paper is organized in the following way. Section 2 gives more information on the language, data, and methodology used for this study. Section 3 is devoted to morphology of the Enets split system proper: Section 3.1 describes the formation of each of the two intransitive paradigms and comments on the formation of transitive paradigms, Section 3.2 presents the Enets viewpoint aspect and discusses the connection between the two intransitive paradigms and aspect, and Section 3.3 describes morphological derivations that change the paradigm choice of an intransitive verb. Section 4 is devoted to lexical issues of the split: Section 4.1 reveals the class variation possibility that exists for a small number of Enets verbs, Section 4.2 ponders the connection of the intransitive paradigms to transitivity and transitive paradigms, and Section 4.3 gives an overview of the lexical distribution of Enets intransitive verbs by the two intransitive paradigms. Section 5 compares how the Enets intransitive split separates all verbs into two classes against other known types of intransitive splits. Section 6 offers concluding remarks.

\section{Language, methodology, and data}

Enets is a highly endangered Northern Samoyedic language that used to be spoken along the lower Yenisei River in the north of Central Siberia, in the Tajmyr municipal region of Russia. There are no more than 50 Modern Enets speakers, all over 50 years old; the language stopped being widely used on an everyday basis in the 1990s and is no longer transmitted to children.

The Enets people are represented by two groups with different self-nominations and different identities, Forest Enets (FE) and Tundra Enets (TE), each speak- 
ing a separate dialect. Linguistically, the two dialects are quite close, and we describe them together, see however Siegl (2013) claiming them to be two different languages. The most salient differences between FE and TE are in phonology, basic lexicon, and pronominal system, with only a couple of divergent morphosyntactic categories and mainly identical morphosyntax. However, since there is no ad hoc knowledge for each morphosyntactic feature whether it is actually identical in the two dialects or different, we keep the data for the two dialects separate in this paper to convince the reader that the intransitive split is actually organized in the same way in the two Enets dialects, unlike e. g. their closest relative Tundra Nenets.

Typologically, Enets is a rather typical Uralic language with suffixal morphology, SOV word order, accusative alignment, double marking (both head and dependent marking) in the clause and NP, extensive verbal morphology specified for various tenses and moods, and non-finite verb forms used for subordination. Like its sister Samoyedic languages, Enets has quite complex morphophonology combined with an otherwise fairly agglutinative structure. Recent grammars of Enets include Sorokina (2010) and Siegl (2013), both limited to the description of FE only.

The research reported in this paper is based on an annotated corpus of Enets that the authors have been creating since 2008. It consists of 32 hours / 40000 clauses of natural speech (25 hours / 30000 clauses for FE and 7 hours / 10000 clauses for TE). The corpus consists, first, of fieldwork recordings done in 2005-2010 by the authors with the assistance of Maria Ovsjannikova, Natalya Stoynova, and Sergey Trubetskoy, and second, of digitized legacy recordings of the previous generation of Enets speakers made in the 1960s-1990s by linguists Kazimir Labanauskas, Eugen Helimski, Irina P. Sorokina, and Darja S. Bolina, by a musicologist Oksana E. Dobzhanskaja, and by an Enets journalist of the local radio Nina N. Bolina. Both modern and legacy recordings were first transcribed in ELAN by the authors, Maria Ovsjannikova, Natalya Stoynova, Sergey Trubetskoy, and our community collaborators Zoja N. Bolina and Viktor N. Pal'chin, and then glossed and edited by the authors in Toolbox software (Buseman and Buseman 2003-2018); each text has a corresponding metadata entry in a plain XML file. The corpus is archived at the ELAR archive. ${ }^{5}$ The Enets corpus consists of various genres and text varieties (Biber and Conrad 2009: 5, 40): everyday stories, traditional stories and tales, dialogues and interviews, procedures and instructions, biographies, songs (listed in decreasing order of their share in the corpus). Though a great effort had been taken to make the corpus as genre balanced as possible,

5 http://elar.soas.ac.uk/deposit/0302 (14. 01. 2019). 
one has to bear in mind that the language is not used anymore by the remaining speakers, so most modern recordings had to be done in a somewhat unnatural setting, and the authors and their fellow fieldworkers had to limit themselves to what was possible to record in those circumstances. Quite comprehensibly, the speakers were more eager to tell everyday stories than traditional narratives, simply because they did not remember that many of the latter. ${ }^{6}$

Corpus-based studies for underdescribed languages of the world are becoming a norm as they give results of a higher quality and facilitate accountability and verification (cf. Bright 2007; Broeder et al. 2011; Chelliah 2001; Himmelmann 1998; Mithun 2014; Mosel 2014), this change being conditioned first of all by technical advances that have made compilation and handling of corpora much easier than a couple of decades ago, but also by the emergence of a new field in linguistics, language documentation. Harrison et al. (2008: 3) even announced "a paradigm shift towards a new empiricism and holism in linguistics" meaning that more and more linguistic studies use corpus data as the main source of information on a language. However, necessary generalizations in grammaticography are still lacking: not much is known about what can and cannot be described with the help of a corpus of an indigenous language. The issue is however pressing, given that typical sizes of indigenous languages' corpora are not comparable to the sizes of corpora of major European languages. Hence this paper also has a methodological goal, besides the description of the mechanisms of the Enets intransitive split and its placement into a semantic typology of split intransitivity systems: to check the limits of a study of an intransitive split, or any other lexically defined morphological feature, based exclusively on data from a relatively large fieldworker's corpus.

There are two reasons why we do not use elicitation or any other experimental data for the study. First, Enets is not used on an everyday basis, and this makes elicitation quite unreliable: while wordlists and paradigms can be collected from some speakers, their grammaticality judgements sometimes contradict real linguistic structures attested in the corpus. Second, as Kemmer (1993: 21) shows, some degree of synchronic variation between the middle class and the unmarked class of verbs is typical cross-linguistically, ${ }^{7}$ so this area is generally fuzzy. We

6 The corpus continues to be updated, edited, and corrected, and the authors are always ready to share the latest version with anyone interested in the language. Besides, an older version of the FE part of the corpus is available on the Internet: http://larkpie.net/siberianlanguages/recordings/ forest-enets (14. 01. 2019).

7 Cf., for example, variation of some Russian verbs, like var'irovat' var'irovat'sja 'to vary' or French examples provided by Kemmer (1993: 21): L'eau bouille $\sim$ se bouille 'The water boils', Le glace fond se fond 'The ice melts'. 
have experience of eliciting data for the intransitive split in Tundra Nenets, a much healthier Samoyedic language still used by our consultants, and this experience is also not positive. It was quite hard for speakers to judge the acceptability of a verb form with an alternative cross-reference marking as opposed to just using it spontaneously on their own.

\section{Morphology of the intransitive split in Enets}

\subsection{Intransitive paradigms in Enets verbal morphology}

Enets verb has a quite complex morphology: some inflectional classes distinguish up to six different stems in FE and up to four in TE, and derivational markers have no surface form in some stems. The most simple verbal form is Indefinite tense, that in our morphological analysis has no segmental marking, but uses the longest stem; Indefinite tense is not glossed in this paper similarly to other features with zero expression, e. g. Nominative or 3SG.

Enets has cross-reference marking for subject that includes three persons and three numbers (singular, dual, plural); the number of the third person object can also be indicated. Cross-reference marking series of two kinds are distinguished: - $\quad$ four tense-modal series: basic, imperative, past, contrastive; ${ }^{8}$

- four indexation series: subjective, subjective-objective for singular object, subjective-objective for non-singular object, middle.

Transitive verbs can take subjective or subjective-objective indexation series, and the choice depends on discourse properties of their object. Intransitive verbs can take subjective or middle indexation series, and the choice is defined lexically. Importantly, all tense-aspect series distinguish the two intransitive paradigms, subjective and middle, ${ }^{9}$ and none of them can be described as derived from the other one. Table 2 shows the two intransitive paradigms for the basic tense-modal series of cross-reference affixes, exemplified above in (1)-(2).

In all tense-modal forms, except 2sG Imperative forms, the two intransitive paradigms differ not only by the form of cross-reference affixes, but also by a special middle formative - $e$ - going immediately before the cross-reference. Since there

8 The past and contrastive series of cross-reference affixes are derived, at least historically, from the basic series, while the imperative series is morphologically independent, see Khanina and Shluinsky (2015).

9 Except for 2SG Imperative form of the main negative verb. 
Table 2: Subjective and middle cross-reference affixes of basic tense modal series. ${ }^{10}$

\begin{tabular}{|c|c|c|c|c|}
\hline & \multicolumn{2}{|c|}{ Subjective cross-reference series "s" } & \multicolumn{2}{|c|}{ Middle cross-reference series " $M$ " } \\
\hline & Forest Enets & Tundra Enets & Forest Enets & Tundra Enets \\
\hline $1 \mathrm{SG}$ & $-z o P,-z P^{11}$ & $-z o P,-z ?$ & $-j P,-b i r,-b ?$ & $-j ?,-b o P,-b ?,-o ?$ \\
\hline $2 \mathrm{sG}$ & $-d$ & $-d o,-d$ & $-d^{j}$ & $-d o,-d$ \\
\hline $3 s \mathrm{sg}$ & $-\varnothing$ & $-\varnothing$ & $-z o P,-z ?$ & $-z O P,-z ?,-?$ \\
\hline 1DU & $-j P,-b i r,-b ?$ & $-j ?,-b i r$ & $-n^{j} i P,-n^{j} P$ & $-n^{i} i p$ \\
\hline 2DU & $-r i ?$ & -ri? & $-z i ?$ & -zi? \\
\hline 3DU & $-x i p$ & -xa?, -xo?, -xi? & $-x i p$ & $-x 0 ?$ \\
\hline $1 \mathrm{PL}$ & $-a ?$ (-כ? / -e?), -ba? & $-a ?,-b a ?$ & $-n a ?$ & $-n a ?$ \\
\hline $2 \mathrm{PL}$ & $-r a ?$ & $-r a ?$ & $-z a ?$ & $-z a ?$ \\
\hline $3 \mathrm{PL}$ & $-?$ & $-?$ & $-z o ?,-z ?$ & $-z o ?,-z ?$ \\
\hline
\end{tabular}

are middle Imperative forms without this formative, we analyze it as secondary and the cross-reference paradigm as primary in the synchronic splitting of Enets intransitive verbs into the two classes. This formative is attached either to the last verbal affix before the cross-reference (3), or to the lexical stem itself, if it bears no other affixes except cross-reference, as in (2).

$$
\begin{aligned}
& t f \text { inadii<...> miiro bese-xone } \quad k u \quad \text { enetfe? } \\
& \text { now what money-Loc.sG where_to person } \\
& \text { taa-d-e-zo?, } \quad \text { mii-gone } \\
& \text { reach.PFV-FUT-M-3SG.M what-LOC.sG } \\
& \text { 'Now <...> what money will a man travel with, with what?' }
\end{aligned}
$$

There are a number of phonological adaptations to the middle formative that involve the last vowel of the stem, and the exact processes depend on the quality of the last vowel and the inflectional class of the verb. ${ }^{12}$ We will not go into very

10 Allomorphs separated by a comma are free variants; allomorphs in brackets are conditioned by the phonology of the stem they are attached to.

11 In FE, non-reduced phonetic variants of the affixes for 1sG.s, 1DU.s, 1SG.M, 3sG.s, 1DU.M, 3PL.M, which feature high vowels, are realized very rarely both in natural and elicited speech, so we keep the spelling of the reduced variants in the orthography of FE examples in this paper. In contrast, in TE the non-reduced variants of the same affixes are rather frequent, so orthography of TE examples in this paper does not reflect the phonetics of the affixes, but always gives the non-reduced variants. The latter is true for orthography of all lexemes, both FE and TE: with consistency of the orthography in mind, we present them in their non-reduced variants, though some vowels may be phonetically reduced or even deleted in actual speech.

12 Since they belong to phonology, these processes have minor differences in the two Enets dialects. Below we describe common principles attested in the both dialects. 
minute details here, but we will present the overall principle of the middle forms building.

All Enets verbal stems are vowel-final, so the middle formative can be attached to the last vowel of the stem with or without the deletion of this vowel, cf. (2)-(3) vs. (4). When the last vowel of the stem is kept intact before the middle formative, the latter can be pronounced as a glide [j], and not as usual [e] or [i], cf. (4). ${ }^{13}$

(4) ent $\int e u-?$ neru-e-z? [nerujz?]

FE

person-PL stand_up.PFV-M-3PL.M

'The people woke up'.

If the last vowel is /e/ or / $\mathrm{i} /$, the middle formative can merge with it, so that no apparent change in the verb form is observed, as compared to a form without the middle formative, $\mathrm{cf}$. (5) vs. (6).

Semini-da

pedi-d-e-z?

$n^{j}$ itka-r

FE

self-oBL.SG.3SG burst.PFV-FUT-M-3SG.M thread-NOM.SG.2SG

'The tread will burst itself.'

(6)
tun $^{i} i-j ?$
pedi-z?
gun-NOM.SG.1SG burst.PFV-3SG.M
'My gun shot.'

FE

For some types of final vowels, two alternative variants may be possible, either for different verbs, cf. (7) vs. (8) for $a$-final verbs, or for one and the same verb, $\mathrm{cf}$. (4) and $(9)^{14}$ for an $e$-final verb.

tfinadi burano-ba?

... loxa-e-tfi

TE

now snowmobile-NOM.SG.1PL

break_down.PFV-M-3SG.M.PST

'Now our snowmobile ... broke down'.
a. aga kaasa nes-j?
modii kol-xoz
big man child-NOM.SG.1SG I school-ABL.SG
naar-e-zodi
stop.PFV-M-3SG.M.PST
'My elder son quitted school.'

TE

13 In non-first syllables, all Enets /e/ can be realized both as [e] and as [i].

14 There are very few verbs of this type - allowing two alternative variants - in TE, and significantly more of them in FE. This may be connected to the more archaic phonology of TE or to the bigger size of the FE subcorpus that makes this rare variation easier to spot. 
b. teada-go-o naara-bu-na?

graze_reindeer.PFV-DUR-NMLZ stop.PFV-CVB.COND-OBL.SG.1PL

$\operatorname{kad}^{j} a-a$

kane-obi-a?

hunt.IPFV-NMLZ leave.PFV-HAB-1PL.S/SOSG

'When we finish watching the reindeer, we go hunting.'

(9) kiuz-noju n'e-? ner-e-z?

morning-ADV child-PL stand_up.PFV-M-3PL.M

'In the morning the children woke up'.

Sentences (10)-(12) exemplify Enets cross-reference series used with transitive verbs: subjective-objective for singular object (10) and subjective-objective for non-singular objects (11)-(12). The person and number of a subject and the singular vs. non-singular number of an object are expressed cumulatively in one cross-reference affix.

ese $n^{j} i$ - $? \quad$ diaxara-bo $^{j}$

TE

father name-obL not_know.IPFV-1SG.SosG

'I do not know (his) father's name.'

fize-if tcne-xu-n

FE

tWO-TRANSL knOW.IPFV-SODU-1SG.SONSG

'I know them both.'

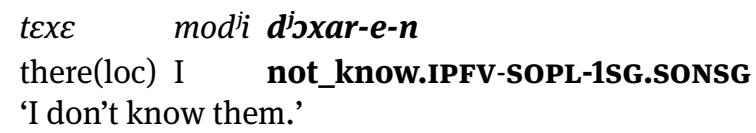

Cross-reference affixes for dual and plural objects are actually the same, and the dual vs. plural number of the object is distinguished only by an affix going before the cross-reference: it is FE - $x u$ - / TE - $x u u$-for dual objects (11) and - $e$-for plural objects (12); the latter is not used in 2SG Imperative forms, similar to the middle marker - $e$-. Though we gloss the plural object affix and the middle formative differently in this paper, they are formally the same and involve the same phonological adaptations depending on the last vowel of the stem. ${ }^{15}$

15 Literature on Enets provides controversial answers to whether they are one morpheme or two different ones. Prokof'ev (1937: 88) and Urmančieva (2012) claim the plural object marker and the middle marker to be the same, Tereščenko (1966: 449), Sorokina (1975: 88, 93, 95) and Siegl (2013: 252-258) speak of two different entities. Moreover, Siegl (2013: 252, 255) analyzes the middle and the plural object formatives as parts of the corresponding cross-reference affixes and not as independent morphological objects. The other Northern Samoyedic languages also have one and the same marker for plural object and middle forms, see Salminen (1997: 102-103) for details 


\subsection{Intransitive split and aspect}

Enets is a language with a derivational viewpoint aspect. By such definition we mean that perfective or imperfective aspectual interpretation is an inherent property of a verbal lexeme, see "PFV" or "IPFV" notation in glosses throughout the paper. In order to apply a different viewpoint to the same event, a new verb is derived by a perfectivizing or an imperfectivizing derivation. Slavic languages are the most well-known languages with a derivational viewpoint aspect, but they are by no means the only ones; more details on derivational viewpoint aspect systems crosslinguistically may be found in Arkadiev and Shluinsky (2015), and on the Enets aspect, in particular, in Shluinsky (2017) and Siegl (2011). Derivational viewpoint aspect is a common Samoyedic feature, see Nikolaeva (2014: 45) for Tundra Nenets, Gusev (2012) for Nganasan, and Kuznecova et al. (1980: 209-210) for Selkup.

Any Enets verb is either perfective or imperfective, and, with extremely few exceptions, never both or indeterminate. By perfective verbs we mean verbs that express an event as "a single whole, without distinction of the various separate phases that make up that situation" (Comrie 1976: 16), while under imperfective verbs we mean the verbs that "pay essential attention to the internal structure of the situation” (Comrie 1976: 16). This distinction is especially clear in Indefinite tense, as perfective verbs in Indefinite tense have past time reference (13), (15), and imperfective verbs in Indefinite tense have present time reference (14), (16). Examples below illustrate Enets verbs with similar meanings, but distinct aspects: cf. FE perfective buzis- 'look.PFV' (13) and imperfective seyir- 'watch.IPFV' (14), as well as TE perfective l'umo- 'get frightened.PFV' (15) and imperfective piis- 'be afraid.IPFV' (16).

tJz buzi?-e-za

$a n^{j} i \operatorname{man}^{j}$

FE

so look.PFV-SOPL-3SG.SONSG and say

'He looked at them again, say.'
$d^{j}$ วxara-da
ente? senina
not_know.IPFV-PTCP.sIM person watch.IPFV.3SG.S
'The stranger is watching.'

FE

\footnotetext{
on Nenets and Helimski (1994: 216, 221) for details on Nganasan, though the difference between Nganasan cross-reference affixes in subjective and middle paradigms indicate that at some point of Nganasan history, the two markers were clearly different (Valentin Gusev, p.c.). Besides, the special marking for plural objects exists only in Northern Samoyedic, while middle marking has its parallels in Hungarian, and so is much older (see Helimski 1982), and this indirectly points to the different origin of the plural object marker and the middle marker. Note that in his historical study, Mikola (2004: 123-127) does not make any direct claims about the common or uncommon origin of the Northern Samoyedic plural object marker and the middle marker.
} 
modi mona-zo?, tee-n ${ }^{i} i$ liumo-e-zo?

$\mathrm{TE}$

I say.PFV-1SG.S reindeer-PL.1SG get_frighten.PFV-M-3PL.M

'I say, my reindeer got frightened.'

(16) miiro piipa-do,

kane-?

$\mathrm{TE}$

what be_afraid.IPFV-2sG.s leave.PFV-2SG.S.IMP

'What are you afraid of? Go!'

Enets perfective intransitive verbs can belong either to subjective class (17)-(18), or to middle class (15), (19)-(20).

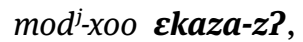

$$
\begin{aligned}
& k o l j a \\
& \text { I-FOC get_tired.PFV-1sG.s Kolja }
\end{aligned}
$$$$
\text { FE }
$$

ee-xo-nit tra-zo?, ee-raxa-j? TE

mother-DAT.SG-OBL.SG.1SG come.PFV-1SG.S mother-CMP-NOM.SG.1SG 'I came to my mother, my step mother she is.'

$$
\text { noxo-e-b? }
$$

perspire.PFV-M-1SG.M

'I perspired.'

$$
\begin{array}{llll}
\text { mora-do } & \text { eग? } & \text { taa-e-zoP } & \text { toto-reo } \\
\text { bank-DAT.SG } & \text { here } & \text { reach.PFV-M-3SG.M } & \text { also-RESTR }
\end{array}
$$

'He came here to the bank as well.'

Imperfective intransitive verbs belong to the subjective class only, cf. (14), (16), and (21)-(23), apart from a close set of infrequent exceptions driven by specific combinations of a morphological and a semantic feature.

$$
\text { tfike kafi-za pifina-? }
$$

this man-NOM.PL.3SG laugh.IPFV-3PL.s

'These mates of him are laughing.'

$$
\begin{array}{ll}
\text { ne-xone } \quad \text { spte?a } \\
\text { woman-LOC.SG } & \text { smell.IPFV.3SG.S }
\end{array}
$$

'It smells of a woman.'

$$
\begin{array}{lll}
m \varepsilon-t a & m e J n & \text { tori } \text { mosara-z? } \\
\text { tent-OBL.SG.3sg in so work.IPFV-1sG.s }
\end{array}
$$

FE

'So I work around her house.'

All of the unexpected imperfective middle verbs belong to derivates, with an exception of one complement-taking verb. We study all the three cases of imperfective middle verbs below. 
Firstly, Forest Enets has three productive imperfectivizing derivations that turn a perfective verb into an imperfective: Multiplicative $-r$ - (- $\eta \boldsymbol{a}$ - in Indefinite tense), meaning a multi-phase event, Durative -go-, meaning a durated event, and Discontinuative -ga-, meaning an event repeated from time to time. When the first of them, Multiplicative $-r$-, is attached to a middle verb, the resulting verb is a subjective imperfective verb, see (24). However, when the two others are attached to a middle verb, the resulting verbs are middle imperfective verbs (25)-(26), though this combination is actually rare in the FE subcorpus: eight tokens for Durative and sixteen tokens for Discontinuative in the Indefinite tense. Tundra Enets has only two productive imperfectivizing derivations, Multiplicative -ro- (- $\eta a$ - in Indefinite tense) and Durative -go-, and none of them has been so far attested with a middle verb. ${ }^{16}$

a. $n \varepsilon \quad a d-e-z$ ? FE woman sit_down.PFV-M-3SG.M

'The woman sat down.'

b. a kere-tu? tวэ-noju <...> to baru-d and self-OBL.SG.3PL summer-ADV lake border-DAT.SG

adu-na-? sit_down.PFV-MULT-3PL.S

'And themselves, in summer they settle themselves at the shore of the lake.'

a. kodi-xi-na?

toj-e-na?

FE

sledge-DAT.PL-PL.1PL reach.PFV-M-1PL.M

'We reached our sledges.'

b. kodi-na? keu-d toz too-go-e-na? an ${ }^{j i}$

sledge-PL.1PL side-DAT.SG so reach.PFV-DUR-M-1PL.M and

'We are reaching our sledges.'

(26) $k \supset \int k \jmath \int e-r \quad$ tori $a n^{i} i d^{j} \supset b u-g a-z a$,

Koshkosh-NOM.SG.2SG so and catch_up.PFV-DISC-3sG.SosG

$a n^{j} i$ adu-g-e-z?

and sit_down.PFV-DISC-M-3sG.M

'Koshkosh all the time reaches him again and sits down again.'

16 We remind here that the Tundra Enets subcorpus is three times smaller than the Forest Enets subcorpus, and so it is not so surprising that the rare combinations have not been attested there. 
Secondly, a productive Passive $-\mathrm{ra}^{-1}{ }^{17}$ always takes middle cross-reference affixes (as also described in Siegl 2013: 259). Usually Passive is used with perfective verbs, but it has been very rarely attested attached to imperfective verbs, as in (27)-(28) (only a handful of such examples in our corpus in contrast to over 200 Passive examples with perfective verbs).

tori poni-la-ubi-nat , aga, aga

FE

so do.IPFV-PASS-HAB-1PL.M.PST big big

mense-na? tone-t $\int \quad$ tonne-du?

old_woman-PL.1PL there_is.IPFV-3PL.S.PST once-OBL.SG.3PL

'So we were treated, there were once old, old women among us.'
tea-da
no?ว-bi-za
kugoj-xozo-da,
$\mathrm{TE}$
reindeer-OBL.SG.3SG catch.PFV-PRF-3SG.SOSG throat-ABL.SG-OBL.SG.3SG
tea-xa-da
uxe-l-e-zo?
reindeer-DAT.SG-OBL.SG.3SG drag.IPFV-PASS-M-3SG.M
'It (=the wolf) grasped the reindeer by its throat, it is being dragged by the reindeer.'

Finally, when an imperfective subjective verb koma- 'want.IPFV' takes a clausal complement with a middle verb, it can manifest middle cross-reference inherited from the embedded verb, cf. (29)-(30). This is the only option attested in FE, while in TE default subjective cross-reference is also possible, see (31). When the middle cross-reference is inherited, we see an imperfective middle verb.

a. गro? $m u-j ?$

$d^{j} a x a-x a-n^{j} i ?$

$a n^{j} e ?$

TE

before PLC-NOM.SG.1SG river-DAT.SG-OBL.SG.1SG and

\section{taa-e-bo?}

reach.PFV-M-1SG.M

'I came to that first river again.'

b. $i$ teina-do taa-do koma-obi-o?

and so-DAT.SG reach.PFV.NMLZ-DAT.SG want.IPFV-HAB-1SG.M

'I want to go there.'
a. mense-za
pe-d
SOPJ-e-z?
old_woman-NOM.SG.3SG outdoors-DAT.SG jump.PFV-M-3SG.M
'His wife jumped outdoors.'

FE

17 In the examples - $l(a)$ - can actually be seen, this is conditioned by the inflectional class of the verb the affix is attached to (many other Enets affixes exhibit a similar behavior depending on the inflectional class, e. g. Inchoative discussed below). 
b. tu nin taruf so?ว-ว-d kom-e-z?

fire onto similar jump.PFV-NMLZ-DAT.SG want.IPFV-M-3SG.M 'She looks like wanting to jump into the fire.'

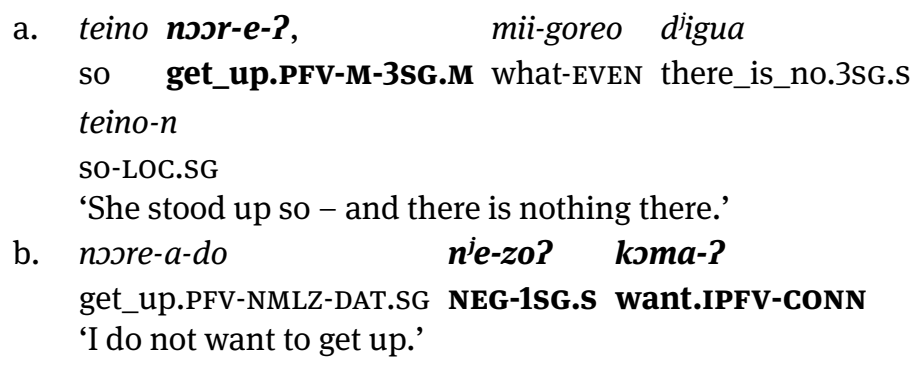

Summing up, all middle verbs are perfective, with rare enumerable exceptions, and subjective verbs can be perfective or imperfective (though among underived intransitive verbs imperfective subjective verbs are more numerous than perfective subjective verbs). Turning it the other way round, all imperfective intransitive verbs are subjective, again with few exceptions, and perfective intransitive verbs can be subjective or middle, though perfective subjective verbs are somewhat more numerous than perfective middle verbs.

\subsection{Aspectual derivations changing the class membership of an intransitive verb}

Enets has two synchronic aspectual derivations that change the class membership of a given intransitive lexeme. One of them, the Multiplicative, has already been mentioned above. The other is Inchoative, working in the opposite direction and also mentioned in Siegl (2013: 259) as a derivation changing class membership. Other aspectual derivations have no power to change the class membership of an intransitive verb.

The Inchoative affix FE -ru- / TE -rio- marks the initial point of an event and produces a perfective verb. Inchoative always requires middle series when attached to intransitive verbs. ${ }^{18}$ Most often, Inchoative is attached to imperfective verbs, and in all these cases it changes the class of the verb from subjective to middle.

18 This property of Inchoatives is also shared by Tundra Nenets (Nikolaeva 2014: 45-46), but not by Nganasan (Tereščenko 1979: 244). 
a. $a n^{i} i$ naara-za

nau?s,

$\mathrm{FE}$

and back_side_of_the_skin-NOM.SG.3SG be_thick.IPFV.3sG.s

se?i-za

be_hard.IPFV-PTCP.SIM.3SG.S

'Its back side is also thick and heavy.'

b. fize d'eri kan'e-e-xaz salba-za

two day leave.PFV-NMLZ-ABL.SG ice-NOM.SG.3SG

nau-l-d-e-z? iblicjgu-on

be_thick.IPFV-INCH-FUT-M-3SG.M small-PROL.SG

'Two days later, the ice will become a bit thicker.'

a. tfinadi sei-xone tuuna sptfiko-one szi-?

$\mathrm{TE}$

now eye-LOC.SG still bad-PROL.SG be_visible.IPFV-3PL.S

'Besides, they (= the scales in the shop) are now hard to see with eyes.'

b. siruba-za ozi-rio-zo?

ice-NOM.SG.3SG be_visible.IPFV-INCH-3SG.M

'The ice appeared.'

Rarely (13 tokens in FE subcorpus, no tokens in TE subcorpus), Inchoative is attached to perfective verbs, as in (34). In all such cases attested in the corpus, original perfective verbs are subjective verbs, so we have not seen cases of Inchoative attached to an originally middle perfective verb, though derived middle perfective verb is expected in this case, as well.
a. dieri ma? peufuma, $a n^{i} i \ldots$
day indeed fall_night.PFv.3sG.s and
'A day, say, is finished...'
b. uze peufu-l-e-z?
$a n^{j} i$
already fall_night.PFV-INCH-M-3SG.M and
$m \varepsilon-k o-d a$
son-e-z?
tent-DAT.SG-OBL.SG.3SG go_back.PFV-M-3SG.M
'The night fell already, and he came back home.'

Multiplicative FE - $r$ - / TE -ro- (- $\eta a$ - in Indefinite tense) expresses a multi-phase event and produces an imperfective verb. If attached to an intransitive verb, whether subjective (35)-(36) or middle (37), imperfective (35) or perfective (36)-(37), Multiplicative always produces a subjective verb.
a. tona salba-d
$k a n^{j} e-e-x a z$
$a n^{i} i$, ed
yet ice-obL.SG.2SG leave.PFV-NMLZ-ABL.SG and so
diazu-da-?
go.IPFV-FUT-3PL.S

FE 
'After the ice yet disappears (= goes away), they (= wild reindeer) will go this way.'

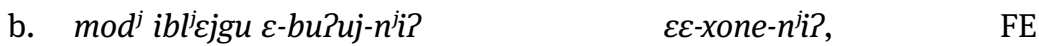

I small be.IPFV-CVB.SIM-OBL.SG.1SG mother-LOC.SG-OBL.SG.1SG

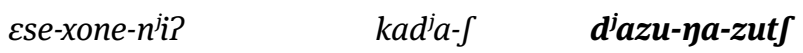

father-LOC.SG-OBL.SG.1SG hunt.IPFV-CVB go.IPFV-MULT-1SG.S.PST

'When I was little, I went hunting with my mother and my father.'

a. a ese-j? pogu-modi $\boldsymbol{k a n}^{j} \boldsymbol{e}$ TE

and father-NOM.SG.1SG fish.IPFV-SUP leave.PFV.3SG.S

'And my father went fishing.'

b. tfinadi tfuku dieri-goa-xone mii?, ne-? kere-tu?

now all life-FOC-LOC.SG what woman-PL self-OBL.SG.3PL

\section{kane-na-?}

leave.PFV-MULT-3PL.S

'Now in this life what, girls marry (= leave) on their own.'

a. nenago-r t $\boldsymbol{t} \boldsymbol{i}-\boldsymbol{e}-\boldsymbol{z}$ ?

FE

mosquito-NOM.SG.2SG fly.PFV-M-3SG.M

'Mosquitos (lit. a mosquito) started flying.'

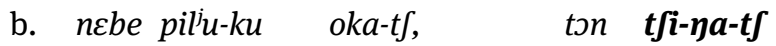

new gadfly-DIM many-3PL.S.PST now fly.PFV-MULT-3PL.S.PST

'There were a lot of new wasps, so they flew around.'

Besides, Gusev (2010) describes a historic Enets Stative marker ${ }^{\star}-w$ - that could also derive imperfective subjective verbs from perfective middle verbs, i. e. it could work in the same direction as Multiplicative. In modern Enets traces of this marker can be seen in pairs of etymologically related verbs that differ, firstly, in their aspect and class membership - subjective and imperfective vs. middle and perfective - and secondly, in the last vowel of the stem (sometimes in FE also in the consonant preceding this last vowel), see (38) for some examples of such verbs and (39)-(40) for illustrations of their usage.

(38) FE bazta- 'lie down.PFV', middle baztfi 'lie.IPFV', subjective,

TE bazeta- 'lie down.PFV', middle bazete- 'lie.IPFV', subjective,

FE $k \supset d a$ - 'fall asleep.PFV', middle $\sim k \supset d i i$ - 'sleep.IPFV', subjective, TE $k J d a$ - ‘fall asleep.PFV', middle $\sim$ kodo- 'sleep.IPFV', subjective,

FE $a d u$ - 'sit down.PFV', middle $\sim$ adii- 'sit down.IPFV', subjective (for TE ado- 'sit down (ipfv/pfv)', subjective / middle see Table 5), 
FE mskata- 'stand up.PFV', middle mskate-/mskat ji- 'stand out.IPFV', subjective

(TE has only mokati- 'stand out.IPFV', subjective)

a. Juzebe-r kod-e-z?

FE

giant-NOM.SG.2SG fall_asleep.PFV-M-3SG.M

'The giant fell asleep.'

b. teza? oor-a-xaz-da Juzebe-r

now eat.IPFV-NMLZ-ABL.SG-OBL.SG.3SG giant-NOM.SG.2

kodii

sleep.IPFV.3SG.S

'Now the giant is sleeping after having eaten.'

(40)
a. i koda-d-e-na?
$d^{j} a a-d u ?$ and fall_asleep.PFV-FUT-M-1PL.M earth-OBL.SG.3PL
diuda-an
middle-PROL.SG
'And we will fall asleep on the way.'
b. kai-zo kodo-za-?
relative-NOM.PL.2SG sleep.IPFV-FUT-3PL.S
'The people will sleep.'

TE

\section{Lexical issues of the intransitive split in Enets}

Below is a description of how Enets lexical stems are distributed along the two classes of intransitive verbs. Section 4.1 is devoted to the few complicated cases when one and the same stem seems to be used with both intransitive paradigms, and to the methodological problems connected to them. Section 4.2 describes detransitivizing derivations involving the middle paradigm. Section 4.3 gives an overview of the lexical distribution of Enets intransitive verbs by classes depending on their meaning.

\subsection{Intransitive class variation}

When one and the same stem looks like it can be used with either one of the intransitive paradigms, it may manifest the difference in aspect (4.1.1), i.e. having imperfective aspect with the subjective paradigm and perfective aspect with the middle paradigm, or there may be no other difference in the two cases beyond the paradigm used (4.1.2). 


\subsubsection{Intransitive class variation with a difference in aspect}

Enets has several pairs of verbs that differ by aspect (perfective or imperfective) and class membership (middle or subjective) only. All such pairs that could be found in our corpus are listed in Table 3, see also examples (41)-(44) illustrating their use.

Table 3: Enets intransitive verbs differing by aspect and class membership only.

\begin{tabular}{|c|c|c|c|}
\hline FE & TE & $\begin{array}{l}\text { Translation as a verb } \\
\text { of subjective series }\end{array}$ & $\begin{array}{l}\text { Translation as a verb } \\
\text { of middle series }\end{array}$ \\
\hline$n \varepsilon-$ & nee- & 'be open.IPFV' & 'open.PFV (intrans)’ \\
\hline ezuzu- & ediuzo- & 'ride.IPFV' & 'leave_riding.PFV' \\
\hline d'iri- & $\begin{array}{l}\text { ire- 'live.IPFV' } \\
\text { (subjective only)' }\end{array}$ & ‘live.IPFV’ & ‘revive.PFV’ \\
\hline d'aru- & $\begin{array}{l}\text { d'aru- 'weep.PFV' }^{\text {(subjective only)' }}\end{array}$ & 'weep.IPFV' & 'begin to weep.PFV' \\
\hline poferi- & $\begin{array}{l}\text { pofteri- 'start whirling.PFV' } \\
\text { (subjective only)' }\end{array}$ & 'whirl.IPFV' & 'start whirling.PFV' \\
\hline soPJ- & - & 'be strong.IPFV' & 'become strong.PFV' \\
\hline $\begin{array}{l}\text { toru- 'close (pfv, } \\
\text { transitive only)' }\end{array}$ & toro- & 'be closed.IPFV' & ‘close.PFV (intrans)’ \\
\hline
\end{tabular}

(41)

a. no-ni? padi $n \varepsilon \varepsilon$

FE

door-obL.SG.1DU flap be_open.IPFV.3sG.s

'The flap of our door (of the tent) is open.'

b. a tfike no-r ne-bi-z?

and this door-NOM.SG.2sG open.PFV-PRF-3SG.M

'And that door opened.'

(42)

a. kanu-ta,

$d^{j}$ goode $d^{j} a-x a n$

diri-da

FE

leave.PFV-FUT.3SG.S another place-LOC.SG live.IPFV-FUT.3SG.S

'S/he would leave, s/he would live in another place.'

b. kameru ent $\int e$ ? kuni diri-d-e-z?

deceased person how revive.PFV-FUT-M-3SG.M

'How would a dead person become alive?'

a. niea-za nee-fi

TE

door-NOM.SG.3SG open.IPFV-3SG.S.PST

'The door was open.'

b. kudaxaa? bi? yu? tfas-xone lapka nee-obi-zo? for_a_long_time ten one hour-LOc.sG shop open.PFV-HAB-3SG.M 'The shop used to open at eleven o'clock.' 
a. pekarn'a nee,

a magazin toro

TE

bakery open.PFv.3SG.s and shop close.PFV.3SG.S

'The bakery is open and the shop is closed.'

b. modii an'e? lapka-xa-do

I and shop-DAT.SG-OBL.SG.2SG

$d^{j} a z o-d a-x a-n^{j} i$,

yobtfike toro-e-zo?

go.IPFV-PTCP.SIM-DAT.SG-OBL.SG.1SG anyway close.PFV-M-3SG.M

'When I get to the shop, it will close already.'

In the FE grammatical description (Siegl 2013), FE verbs with similar meanings, but different aspectual value and paradigm choice are also mentioned, though from the list of four such pairs in Siegl (2013: 257-258), only one can be seen in Table 3: diri-. Under a closer phonetic analysis that we have undertaken, the members of two of Siegl's pairs have turned out to have different phonological shapes, to- 'come.PFV (subjective)' vs. toว- 'reach.PFV (middle)', and adii- 'sit down.PFV (subjective)' vs. adu- 'sit down.PFV (middle)', see (38) above. The remaining verb $t f i$ - 'fly.PFV' has only middle uses in our corpus, though the verb itself is quite frequent: there are 22 of its finite uses attested in our corpus. ${ }^{19}$

There are also two pairs of verbs, one in FE and one in TE, see Table 4, that look exactly like those listed in Table 3, but they form Future differently.

Table 4: Enets intransitive verbs differing by aspect and class membership and by the way they form Future.

\begin{tabular}{llll}
\hline FE & TE & $\begin{array}{l}\text { Translation as a verb } \\
\text { of subjective series }\end{array}$ & $\begin{array}{l}\text { Translation as a verb } \\
\text { of middle series }\end{array}$ \\
\hline banu- & $\begin{array}{l}\text { banu- 'lie.IPFV' } \\
\text { (subjective only) } \\
\text { bano- 'lie down.PFV' } \\
\text { (middle only) } \\
\text { ado- }\end{array}$ & 'lie.IPFV' & 'lie down.PFV' \\
$\begin{array}{l}\text { adij- 'sit.IPFV' } \\
\text { (subjective only) } \\
\begin{array}{l}\text { adu- 'sit down.PFV' } \\
\text { (middle only) }\end{array}\end{array}$ & 'sit.IPFV' & 'sit down.PFV' \\
\hline
\end{tabular}

19 While the absence in the corpus can never mean definite absence in the language, we would estimate the probability that a parallel imperfective subjective verb indeed exists in the natural speech as not very high. Siegl's example of the subjective verb $t f i$ - 'fly.IPFV' originates in elicitation, and could be a case of hypercorrection, where the homonymy of some forms of the verb $t f i$ 'fly.PFv' and its Multiplicative derivate $t \int i-r$ - 'fly.IPFV' was extended to other forms (e. g. both are $t / \hat{i}-b i$ in Perfect). 
In Enets, most verbs use the - $d a$ affix for the Future, although some verbs use the $-z a$ affix for the same purpose: the distribution is lexical and not connected to the phonology or the semantics of the verbs. ${ }^{20}$ FE verb banu- used in the subjective paradigm has Future banu-za-, and FE verb banu- used in the middle paradigm has Future banu-da-; TE verb ado- used in the subjective paradigm has Future ado-za-, and TE verb ado- used in the middle paradigm has Future $a d o-d a-{ }^{21}$ This is connected to the fact that the two banu- and the two ado-verbs used to be different in the history of Enets: there was an original middle verb and its Stative ${ }^{\star}-w$ subjective derivate mentioned above, and all Stative ${ }^{\star}-w$ derivates took $z$-initial allomorphs of $d$-initial affixes (Gusev 2010). Now some phonological changes led to the phonological coincidence of the original verbs and their derivates, though the difference in the formation of Future remained.

Note that there have been no Future forms of the FE middle verb banu- 'lie down.PFV' and of TE middle verb ado- 'sit down.PFV' attested in our corpus. It is only elicitation for FE and the dictionary (Helimski 2007) for TE that informed us about the Future form of these verbs. However, this is the kind of data that can definitely be found in a natural text corpus, if the corpus is bigger. Besides, even if we did not know the difference between the verbs in Table 4 and the verbs in Table 3, it would not change the analysis of the grammatical system, but would provide less accurate information on the lexicon. Indeed, for one verb from Table 3, FE SJPJ- 'be strong.IPFV' we do not know its Future form, so it may as well turn out to be different from the Future form so?s-da for so?s- 'become strong.PFV', which we already know.

Except for the handful of verbs listed in Table 3, Enets verbs are always lexically specified for aspect, ${ }^{22}$ so we would expect to find some derivation markers on one of these verbs in variation pairs from Table 3, though they are indeed

20 There are other affixes with the same lexical distribution, e.g. Simultaneous Participle FE $-d a /-z a$, TE -de / -ze, FE Anterior Passive Participle -duuj / -zuuj and Suppositional FE, TE -daraxa / -zaraxa.

21 In both cases listed in Table 4, we know of recent phonetic processes that made the two originally different verbs look the same at the synchronic level. In both Enets dialects, stem-final back open vowels have been turning into close vowels at least for the last 50 years. Comparison of FE form banu- for 'lie (ipfv)' and 'lie down (pfv)' to its TE cognate lexemes illustrates the point: in TE the subjective verb is banu-, while the middle verb is bano-. It reflects the general fact that Tundra Enets phonology is more conservative than Forest Enets phonology. Likewise, if we compare modern TE word ado- for 'sit (ipfv)' and 'sit down (pfv)' with the TE data from the Helimski's (2007) dictionary, reflecting a more conservative language use, there $a d u$-is used as a subjective verb and $a d o$ - is used as a middle verb. For TE we do not see the direct $/ \mathrm{J} />/ \mathrm{u} /$ change, as in the FE case, but a general merge of the final back vowels $/ \mathrm{J} /, \mathrm{o} /$, and $/ \mathrm{u} /$ in the intermediate $/ \mathrm{o} /$.

22 Two exceptions to this rule have been attested in FE: bazis- 'tell.IPFV' 'tell.PFV' and mujs'make.IPFV' 'make.PFV' (Shluinsky 2017: 35-36). 
absent. Likewise, except for this handful of verbs, Enets verbs are always lexically specified for class membership, so the verbs in Table 3 represent a real problem for analysis (unlike verbs in Table 4, whose Future forms indicate clearly that we are dealing with homonyms here, i.e. with different verbs after all). In these pairs, are they two different verbs, with one being derived by the class conversion mechanism from the other (and what is the direction of derivation then?), or are they cases of single verbs with two possible aspects and belonging to two possible classes at the same time? We prefer the first alternative, as it does not presuppose the violation of rules otherwise rigidly working in the grammar of Enets. Besides, we know of one derivation that used to work in Enets a while ago and produced very similar results, namely the Stative ${ }^{\star}-w$, so it could be exactly this derivation, whose phonological traces have been lost by today, or it could be another historic derivation, whose phonological traces have already been lost too. As for the direction of derivation in this case, we leave the question open for the moment, as we know of Enets derivations working in both directions: from middle to subjective, as well as from subjective to middle (see Section 3.3), which means that both directions are imaginable for the verbs listed in Table 3.

\subsubsection{Class variation without any difference in aspect}

Enets also has a handful of perfective intransitive verbs that exhibit variation between the two classes without any apparent change of meaning or aspect:

(45) FE, TE

$k a ? a$ - 'fall down, come down.PFV' (subjective uses are in clear minority, but present in both dialects)

TE

mono- 'fall down.PFV',

taa- 'reach.PFV' (not completely sure of its subjective uses),

to- 'come.PFV' (not completely sure of its middle uses).

\footnotetext{
a. kədo nizo mono-e-bo? sledge from fall_down.PFV-M-1SG.M 'I fell of the sledge.'

b. yu? serobe?J-d'a mona one male_wild_reindeer-PEJ fall_down.PFv.3SG.S 'One male wild reindeer fell down.'
}

TE

These cases allow for two possible analyses: as class conversion with a subtle change of meaning or as pure class variation without any change of meaning. 
As it was already mentioned, Kemmer (1993: 21) showed that some degree of synchronic variation between the middle and the unmarked verb class is typical cross-linguistically for a small number of verbs. So here we opt for the class variation analysis.

\subsection{Connection between middle intransitive verbs and transitive verbs}

\subsubsection{Passive: middle intransitive verbs derived from transitive verbs}

The already mentioned fully productive Passive marker - $r a$ - is the main detransitivizing strategy in Enets. It can be attached to any perfective transitive verb: all passive derivates are intransitive verbs belonging to the middle class.
a. $s b u-u \int$
bogulia-? toza-d what-TRANSL bear-PL bring.PFV-2sG.S
'Why did you bring bears?'
this be_born.PFV-CAUS-DUR-PTCP.ANT woman
$m \varepsilon-k o-d a$
toza-r-e-z?
b. tfike sjja-ta-go-j ne
tent-DAT.SG-OBL.SG.3SG bring.PFV-PASS-M-3SG.M
'The woman who gave birth was brought home.'

FE

On very rare occasions, Passive can be formed from imperfective verbs, and in Section 3.2 above this was discussed as one of the conditions under which an imperfective middle verb may arise.

\subsubsection{Detransitivizing function of middle?}

Enets has pairs of verbs with the same stem and aspect, but different transitivity: in these pairs the intransitive verb usually belongs to the middle class. Table 5 lists all cases when a verb used with middle series is a detransitive equivalent of a transitive verb.
a. umivaliniku-r
tone?
$u z i-n^{j}$ ?
FE
wash_stand-NOM.SG.2SG there_is.IPFV.3SG.S hand-PL.1SG
masu-xogu-z?
wash.PFV-HORT-1SG.S
'Do you have a wash-stand? I'd wash my hands.' 
Table 5: Enets verbs differing by transitivity, when the intransitive verbs take middle series.

\begin{tabular}{|c|c|c|c|}
\hline FE & TE & $\begin{array}{l}\text { Translation as } \\
\text { a transitive } \\
\text { verb }\end{array}$ & $\begin{array}{l}\text { Translation as an } \\
\text { intransitive verb } \\
\text { of middle series }\end{array}$ \\
\hline nete- & nee- & 'open.PFV' & 'open.PFV' \\
\hline neruta- & $\begin{array}{l}\text { nככrta- 'stop.PFV' } \\
\text { (transitive only) }\end{array}$ & 'stop.PFV' & 'stop.PFV' \\
\hline pize- & $\begin{array}{l}\text { piize- 'frighten.PFV' } \\
\text { (transitive only) }\end{array}$ & 'frighten.PFV' & 'get afraid.PFV' \\
\hline mokata- & $\begin{array}{l}\text { məkata- 'put up.PFV' } \\
\text { (transitive only); } \\
\text { məkati- 'stand out.IPFV' } \\
\text { (subjective only) }\end{array}$ & 'put up.PFV' & 'stand up.PFV' \\
\hline masu- & - & 'wash.PFV' & 'wash oneself.PFV' \\
\hline toru- 'close.PFV' (transitive only) & toro- & ‘close.PFV’ & 'close.PFV’ \\
\hline$d^{\prime}{ }^{\prime} z i-$ 'finish.PFV' (transitive only) & $d^{j} u d^{j} e-$ & 'finish.PFV' & 'finish.PFV' \\
\hline tEkru- 'hide.PFV' (middle only) & tokoro- & 'hide.PFV’ & 'hide.PFV' \\
\hline
\end{tabular}

b. torse bi-kon masu-d-e-d $\boldsymbol{d}^{j}$

such water-LOC.sG wash.PFV-FUT-M-2sG.M

'You will wash yourself with such water.'
a. tfike sola-ku xabiku-ro
tokor-e-za
hide.PFV-SOPL-3SG.SONSG
'This foolish Khabiku hid his fish.'
b. kaa-za tokor-e-zo?
relative-NOM.SG.3SG hide.PFV-M-3SG.M
'His friend hid.'

kare-za

TE

this foolish-DIM Khabiku-NOM.SG.2SG fish-NOM.PL.3SG

Similar pairs of verbs that differ by transitivity only and use the subjective, and not middle, paradigm in their intransitive uses are significantly less numerous: so far, we can list only FE kaji- / TE kae- 'stay somewhere.PFV' (50-a) and FE kaji- / TE kae- 'leave someone somewhere.PFV' (50-b).

a. ese-xuu-za

kae-xuu-za,

father-DU-NOM.PL.3SG leave.PFV-SODU-3sG.SONSG self-oBL.SG.3SG kan'e

leave.PFv.3sG.s

'He left his parents, (and) himself, he went away.' 
b. kaa-j?

$k a n^{j} e-\int i$,

modii eks-xone

relative-NOM.SG.1SG leave.PFV-3SG.S.PST I this-LOc.sG

peri? kae-zo?

most stay.PFV-1SG.s

'My friend left, I stayed here forever.'

There is also a pair of TE verbs with identical stems that differ not only by transitivity, but also by aspect: pofide- 'whirl.IPFV' (intransitive) and pofide- 'make whirling.PFV' (transitive).

\subsection{Lexical distribution of intransitive verbs by the two classes}

As for the lexical choice of subjective or middle series for a given Enets intransitive verb, few predictions can be made based on the meaning of the verb, $\mathrm{cf}$. FE kan'e- / TE kane- 'leave.PFV' (subjective), but FE fimu- 'run away.PFV' (middle), TE kuno- 'run away.PFV' (middle), see (1)-(2). However, there are some trends in the verbal lexicon, and we discuss them here.

Firstly, it has already been said that imperfective intransitive verbs belong to the subjective class, unless very particular conditions are met. Secondly, perfective intransitive verbs with the semantics of change of body posture all belong to the middle class: all verbs of this type attested in our corpus are listed in Table 6.

Table 6: Enets intransitive perfective verbs with semantics of change of body posture (“-” means that no cognate intransitive perfective verb with this semantics has been attested in the TE subcorpus).

\begin{tabular}{lll}
\hline Meaning & FE & TE \\
\hline 'sit down.PFV' & adu- & ado- \\
'get up.PFV' & neru- & nכoro- \\
'stretch out.PFV' & botu- & batuo- / batu-23 \\
'lie down.PFV' & banu- & bano- \\
'lie down.PFV' & bazta- & bazeta- \\
'lie down.PFV' & mכfta- & - \\
'fall on ones belly.PFV' & lotru- & - \\
'stand up.PFV' & mokata- & - \\
\hline
\end{tabular}

23 This TE verb has not been attested in our TE subcorpus, but Helimski (2007) provides reliable evidence that the verb cognate to this FE verb exists in TE with equivalent semantics and that it belongs to the same middle class. 
Finally, perfective intransitive verbs with semantics of motion, non-translational or translational, may belong to both classes, though those belonging to the middle class are somewhat more numerous, e.g. middle FE pokuru- / TE pskoro- 'climb into.PFV', FE $t$ fi- / TE $t$ fio- 'fly.PFV' and subjective FE $t \int u$ - / TE $t \int u$ - 'enter.PFV', FE $k^{\prime}{ }^{j}$ e- / TE kane- 'leave.PFV'. There are also many other middle verbs that do not belong to the two mentioned semantic types - of change of body posture and of motion. These verbs cannot be grouped into any significant semantic types, e. g. FE kadaru- / TE kaadoro- 'fall ill.PFV', FE, stuzu- 'come (about autumn).PFV', FE, TE yaara- 'quiet down.PFV'. For the majority of such verbs, a subjective verb with quite close semantics can be found, e. g. FE $\varepsilon k a z u$ - / TE ekazo- 'get tired.PFV', FE pcufuu- / TE pessuo- 'come (about evening).PFV', FE, TE kaa- 'die.PFV'.

Turning to overall numbers, subjective verbs are definitely more numerous than middle verbs. At the moment, the type frequency of synchronically underived subjective verbs is ca. 290 in our FE subcorpus and ca. 170 in our TE subcorpus, and the type frequency of synchronically underived middle verbs is ca. 65 in our FE subcorpus and ca. 30 in our TE subcorpus, so the subjective verbs are somewhat five times more numerous in the lexicon than the middle verbs. The numbers are approximate since some verbs have been attested in non-finite forms only, and in these forms the intransitive class membership cannot be determined at all; some other verbs have been attested once or twice using one intransitive paradigm, and once or twice using the other intransitive paradigm: in such cases it is not clear whether some forms should actually be analyzed as ungrammatical slips of the tongue on the part of speakers who rarely use their language these days. However, even these approximate values give an idea of the respective type frequencies of the two types of intransitive verbs.

\section{Enets intransitive verbs against the semantic typology of intransitive splits cross-linguistically}

In the beginning of this paper, we suggested to compare the Enets way to split intransitive verbs into two classes with the two other types of intransitive splits: a dedicated morphology for "middle" verbs and active alignment. Now we will contrast the Enets middle class verbs, first, with "middle situation types" (Kemmer 1993), then with a special intransitive class in active alignment languages (Merlan 1985), and finally we will comment on other semantic parameters mentioned in typological literature in connection to intransitive splits. In this discussion, we 
will refer only to perfective intransitive verbs in Enets, as the issue of the split is irrelevant for Enets imperfective verbs, as was shown in the previous sections.

Table 7 shows all "middle situation types” as enumerated by Kemmer (1993) and the class of the corresponding perfective intransitive verbs in Enets (note that many Enets middle verbs do not belong to any "middle situation type" from Kemmer (1993), so they do not appear in Table 7 at all). As can be seen, there is some reason to refer to Enets intransitive verbs using the non-subjective cross-reference paradigm "middle", though there is definitely no full correspondence between these verbs and the classic list of middle situation types.

Table 7: “Middle situation types” from Kemmer (1993) and Enets perfective intransitive verbs with equivalent semantics.

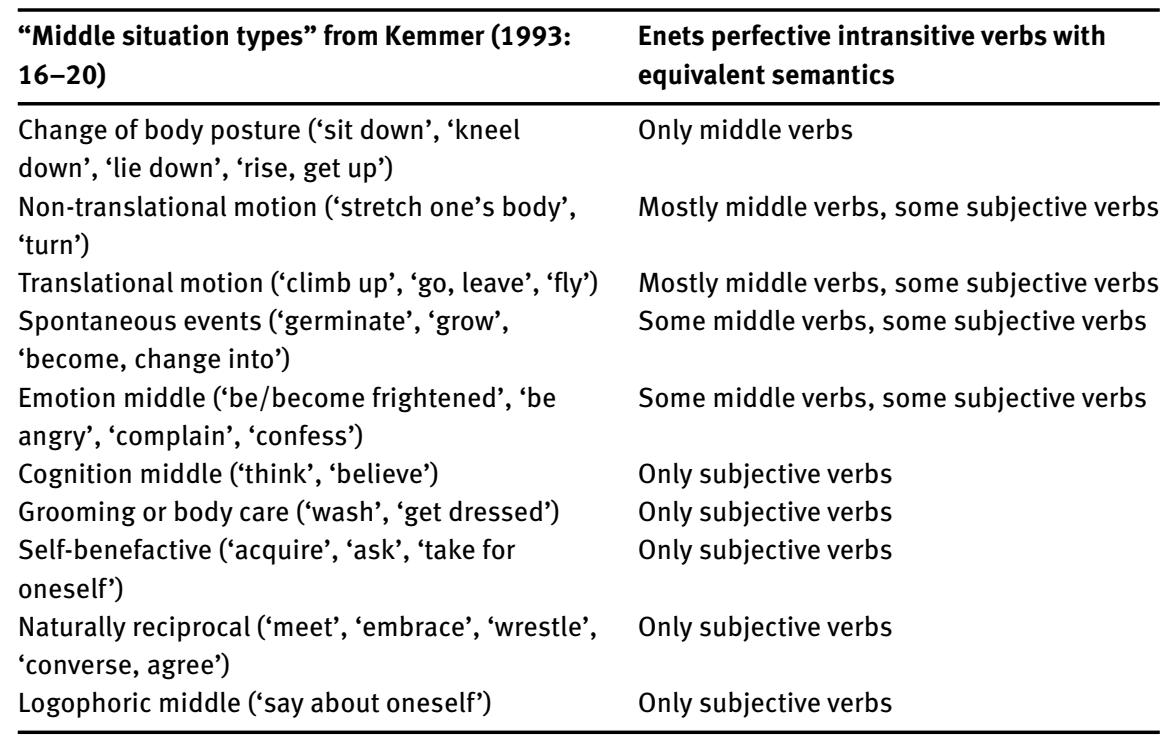

The same conclusion of partial, but definitely not complete fitting into the known cross-linguistic trends may be drawn if one compares the Enets division of intransitive verbs into two lexical classes with the division typical for active alignment systems.

Merlan (1985) has shown that this type of split intransitivity systems distinguishes between default-like vs. special intransitive classes, and verbs of bodily functions or processes are always a part of the special class. The Enets middle class is definitely the smaller one and thus the more special class against the Enets 
subjective class, and the same is presumably true for all middles marked by a dedicated cross-reference paradigm. Verbs of change of posture and verbs of motion, that are middle or mostly middle in Enets, constitute a semantic subclass of bodily functions or processes, but there are bodily functions mentioned by Merlan (such as e. g. 'be hungry', 'be afraid', 'breathe') that are not middle in Enets; verbs of noises and cries mentioned by Merlan, as well, are not middle in Enets, see Table 8 .

Table 8: Verbs always belonging to the special intransitive class from Merlan (1985) and Enets perfective intransitive verbs with equivalent semantics.

\begin{tabular}{|c|c|}
\hline $\begin{array}{l}\text { Bodily functions and processes from Merlan } \\
\text { (1985) }\end{array}$ & $\begin{array}{l}\text { Enets perfective intransitive verbs with } \\
\text { equivalent semantics }\end{array}$ \\
\hline Change of body posture & Only middle verbs \\
\hline Motion & Mostly middle verbs, some subjective verbs \\
\hline Noises and cries & Only subjective verbs \\
\hline $\begin{array}{l}\text { Other bodily functions ('be hungry', 'be afraid', } \\
\text { 'breathe') }\end{array}$ & Only subjective verbs \\
\hline
\end{tabular}

There are some other semantic features that are often mentioned in the literature as relevant to splitting intransitive verbs into two classes: (a) aspect and actionality related to change of state, (b) humanity of the sole argument, (c) agentivity of the sole argument (e. g. see Merlan 1985; Van Valin 1990; Mithun 1991). Enets middle verbs are in line with the aspectual feature: middle verbs are always perfective and denote a change of state, and intransitive verbs with the inchoative marker are always middle. However, they are not in line with the features related to the sole argument: the only argument of Enets middle verbs can be both human and non-human, and both agentive and non-agentive.

\section{Conclusion}

The two classes of Enets intransitive verbs have been described in this paper from morphological and lexical points of view. Before we discuss the contribution of the Enets data to the typological research of split intransitivity, some methodological remarks regarding corpus-based research of underdescribed languages of the world can be made here. The description of the morphology of the Enets intransitive split has shown quite good results both for form building and for derivation 
connections between the two classes, but the description of the lexical distribution has turned out to be more challenging for this type of data. A rough description of the existing lexical and semantic classes is possible, and has been presented above, but an accurate description of each semantic class is yet not feasible, and that is why no exhaustive lists for each semantic class have been provided. Aside from the already mentioned problem with counting the exact numbers of subjective and middle verb types in the corpus, many verbal lexemes were a source of another problem: they were attested no more but a handful of times in the corpus, which is too little to figure out their semantics properly, and thus to ascribe them to a semantic class. However, it looks like there is no inherent problem in this somewhat inadequate description of lexical and semantic classes, as the class membership of the most frequent verbs could actually be determined without any doubts. So, the bigger is the corpus, the more verbs can be described as belonging to each semantic subtype of each intransitive class.

As for the comparison of semantic content of Enets "middle" verbs to corresponding classes in other types of intransitive splits, it has produced the following results, see Table 9. Neither the Enets "middle" verbs, "middle" verbs in other languages described by Kemmer (1993), nor a smaller, distributionally limited class of verbs in active alignment languages described by Merlan (1985), intersect completely. However, two interesting generalizations can be made. First, verbal meanings that belong both to the "middle" verbs in the sense of Kemmer (1993) and to the smaller class of verbs in active alignment languages turn out to be middle in Enets: they are shown in bold in Table 9. Thus, Enets middle verbs cover exactly the intersection of the two cross-linguistically described types of splits, or the core of any cross-linguistically known intransitive split regardless of its morphology (although Enets middle verbs also cover some other meanings). Second, judging by the number of semantic classes not represented among the Enets middle verbs, the smaller class of verbs in active alignment languages is a somewhat better cross-linguistic match for Enets than the middle verbs. This result is unexpected given the morphological side of the Enets intransitive split: formally, it is indeed much more similar to other middle splits known to typology, namely those attested in Greek and Fula (see Section 1.2), than intransitive splits in active alignment languages.

At the same time, the analysis of the Enets data shows that more research is needed in the domain of semantic composition of verbal classes in the case of intransitive splits cross-linguistically. It could be interesting to organize more languages with intransitive splits into a semantic typology, and compare these results to the grouping of the same languages by morphosyntactic criteria. The Enets case suggests that it cannot be predicted in advance whether the ad hoc classification 
Table 9: Enets middle verbs as compared to the two other types of intransitive splits.

\begin{tabular}{|c|c|c|c|}
\hline & $\begin{array}{l}\text { Belongs to the } \\
\text { Enets class of } \\
\text { middle verbs }\end{array}$ & $\begin{array}{l}\text { Belongs to } \\
\text { "middle" verbs by } \\
\text { Kemmer (1993) }\end{array}$ & $\begin{array}{l}\text { Belongs to the } \\
\text { smaller, } \\
\text { distributionally } \\
\text { limited class of verbs } \\
\text { by Merlan (1985) }\end{array}$ \\
\hline $\begin{array}{l}\text { Cognition middle } \\
\text { ('think', 'believe') }\end{array}$ & - & + & - \\
\hline $\begin{array}{l}\text { Grooming or body care } \\
\text { ('wash', 'get dressed') }\end{array}$ & - & + & - \\
\hline $\begin{array}{l}\text { Self-benefactive ('acquire', } \\
\text { 'ask', 'take for oneself') }\end{array}$ & - & + & - \\
\hline $\begin{array}{l}\text { Naturally reciprocal } \\
\text { ('meet', ‘embrace', } \\
\text { 'wrestle', ‘converse, agree') }\end{array}$ & - & + & - \\
\hline $\begin{array}{l}\text { Logophoric middle } \\
\text { ('say about oneself') }\end{array}$ & - & + & - \\
\hline $\begin{array}{l}\text { Spontaneous events } \\
\text { ('germinate', 'grow', } \\
\text { 'become, change into') }\end{array}$ & + & + & - \\
\hline $\begin{array}{l}\text { Emotion middle } \\
\text { ('be/become frightened', } \\
\text { 'be angry', 'complain', } \\
\text { 'confess') }\end{array}$ & + & + & - \\
\hline $\begin{array}{l}\text { Non-translational motion } \\
\text { ('stretch one's body', 'turn') }\end{array}$ & + & + & + \\
\hline $\begin{array}{l}\text { Translational motion } \\
\text { ('climb up', 'go, leave', 'fly') }\end{array}$ & + & + & + \\
\hline $\begin{array}{l}\text { Change of body posture } \\
\text { ('sit down', 'kneel down', } \\
\text { 'lie down', 'rise, get up') }\end{array}$ & + & + & + \\
\hline Noises and cries & - & - & + \\
\hline $\begin{array}{l}\text { Other bodily functions } \\
\text { ('be hungry', 'be afraid', } \\
\text { 'breathe') }\end{array}$ & - & - & + \\
\hline $\begin{array}{l}\text { Other changes of state, e. g. } \\
\text { 'fall ill', 'come (about } \\
\text { autumn)', 'quiet down', etc. }\end{array}$ & + & - & - \\
\hline
\end{tabular}

of languages with intransitive splits into "languages with active alignment" vs. "languages with a dedicated paradigm for middle verbs" has any correlates with semantic grouping of verbs in the two types of languages. 
Acknowledgments: We express our deepest gratitude to the Enets speakers we had the privilege to work with, and to all people who contributed to this collection (the legacy recordings were kindly provided by the Dudinka branch of GTRK “Noril'sk”, Tajmyr House of Folk Culture, Dar'ja S. Bolina, Oksana E. Dobzhanskaja, Irina P. Sorokina, and Anna Ju. Urmančieva), as well as to Maria Ovsjannikova, Natalya Stoynova, and Sergey Trubetskoy for their help in the collection and transcription of Enets texts.

We are grateful to the audience of the 5th International Conference on Samoyedology (Helsinki, October 2014) and to the anonymous reviewers for their valuable comments related to the earlier versions of the paper, as well as to Dasha Shavarina for improving our English.

Funding: The research was conducted in terms of the project supported by Russian Science Foundation, grant No.15-18-00044.

The Enets corpus was prepared as part of the "Documentation of Enets: digitization and analysis of legacy field materials and fieldwork with last speakers" (2008-2011) project supported by the Hans Rausing Endangered Languages Programme (SOAS, London) and later by the Max Planck Institute for Evolutionary Anthropology.

\section{Abbreviations in glosses}

$\begin{array}{ll}\text { 1, 2, } 3 & \text { 1st, 2nd, 3rd person } \\ \text { ABL } & \text { ablative } \\ \text { ADV } & \text { adverb } \\ \text { CAUS } & \text { causative } \\ \text { CMP } & \text { comparative } \\ \text { CONN } & \text { connegative } \\ \text { CVB } & \text { converb } \\ \text { CVB.COND } & \text { conditional converb } \\ \text { CVB.SIM } & \text { simultaneous converb } \\ \text { DAT } & \text { dative } \\ \text { DIM } & \text { diminutive } \\ \text { DISC } & \text { discontinuative } \\ \text { DU } & \text { dual } \\ \text { DUR } & \text { durative } \\ \text { EVEN } & \text { marker 'even' } \\ \text { FOC } & \text { focal } \\ \text { FUT } & \text { future }\end{array}$




\begin{tabular}{|c|c|}
\hline HAB & habitual \\
\hline HORT & hortative \\
\hline IMP & imperative \\
\hline $\mathrm{INCH}$ & inchoative \\
\hline IPFV & imperfective \\
\hline LOC & locative \\
\hline M & middle cross-reference series \\
\hline MULT & multiplicative \\
\hline NEG & negative verb \\
\hline NMLZ & nominalizer \\
\hline NOM & nominative \\
\hline OBL & oblique \\
\hline PASS & passive \\
\hline PEJ & pejorative \\
\hline PFV & perfective \\
\hline PL & plural \\
\hline PLC & placeholder \\
\hline PRF & perfect \\
\hline PROL & prolative \\
\hline PST & past \\
\hline PTCP.ANT & anterior participle \\
\hline PTCP.SIM & simultaneous participle \\
\hline RESTR & restrictive \\
\hline $\mathrm{s}$ & subjective cross-reference series \\
\hline SG & singular \\
\hline SODU & subjective-objective cross-reference marker for dual object \\
\hline SONSG & subjective-objective cross-reference marker for non-singular object \\
\hline SOPL & subjective-objective cross-reference marker for plural object \\
\hline SOSG & subjective-objective cross-reference marker for singular object \\
\hline SUP & supine \\
\hline TRANSL & translative \\
\hline
\end{tabular}

\section{References}

Arkadiev, Peter M. 2008. Thematic roles, event structure, and argument encoding in semantically aligned languages. In Mark Donohue \& Søren Wichmann (eds.), The typology of semantic alignment, 101-117. Oxford: Oxford University Press.

Arkadiev, Peter \& Andrey Shluinsky. 2015. Slovoklassificirujuščie aspektual'nye sistemy: opyt tipologii [Classifying aspect systems: A tentative typology]. Vestnik SPbGU. Serija 9. 
Filologija. Vostokovedenie. Žurnalistika [Vestnik of St. Petersburg State University. Series 9. Philology. Asian Studies. Journalism] 3. 4-24.

Biber, Douglas \& Susan Conrad. 2009. Register, genre, and style. Cambridge: Cambridge University Press.

Bright, William. 2007. Contextualizing a grammar. In Thomas Payne \& David Weber (eds.), Perspectives on grammar writing, 11-17. Amsterdam: Benjamins.

Broeder, Daan, Han Sloetjes, Paul Trilsbeek, Dieter van Uytvanck, Menzo Windhouwer \& Peter Wittenburg. 2011. Evolving challenges in archiving and data infrastructures. In Geoffrey Haig, Nicole Nau, Stefan Schnell \& Claudia Wegener (eds.), Documenting endangered languages: Achievements and perspectives, 33-54. Berlin \& New York: de Gruyter Mouton.

Buseman, Alan \& Karen Buseman. 2003-2018. Field Linguist's Toolbox [computer software]. https://software.sil.org/toolbox (14. 01. 2019).

Chelliah, Shobhana L. 2001. The role of text collection and elicitation in linguistic fieldwork. In Paul Newman \& Martha Ratliff (eds.), Linguistic fieldwork, 152-164. Cambridge: Cambridge University Press.

Comrie, Bernard. 1976. Aspect: An introduction to the study of verbal aspect and related problems. Cambridge: Cambridge University Press.

Dixon, R. M. W. 1979. Ergativity. Language 55(1). 59-138.

Gianollo, Chiara. 2005. Middle voice in Latin and the phenomenon of split intransitivity. Journal of Latin Linguistics 9(1). 97-110.

Givón, Talmy. 1981. Typology and functional domains. Studies in Language 5(2). 163-193.

Gusev, Valentin Ju. 2010. Stativy i dekauzativy na *-w v samodijskix jazykax [*-w statives and anticausatives in Samoyedic]. In Svetlana I. Burkova (ed.), Materialy 3-ej meždunarodnoj naučnoj konferencii po samodistike [Proceedings of the 3rd International Conference on Samoyedology], 54-65. Novosibirsk: Institut filologii SO RAN.

Gusev, Valentin Ju. 2012. Aspekt v nganasanskom jazyke [Aspect in Nganasan]. Acta Linguistica Petropolitana 8(2). 311-360.

Harrison, David K., David S. Rood \& Arienne M. Dwyer. 2008. A world of many voices: Editors' introduction. In David K. Harrison, David S. Rood \& Arienne M. Dwyer (eds.), Lessons from documented endangered languages, 1-12. Amsterdam: Benjamins.

Helimski, Eugen A. 1982. Drevnejšie vengersko-samodijskie jazykovye paralleli [The oldest Hungarian-Samoyedic parallels]. Moscow: Nauka.

Helimski, Eugen A. 1994. Očerk morfonologii i slovoizmenitel'noj morfologii nganasanskogo jazyka [A sketch of Nganasan morphophonology and inflectional morphology]. In Eugen A. Helimski (ed.), Tajmyrskij ètnolingvističeskij sbornik, Tom 1, Materialy po nganasanskomu šamanstvu i jazyku [Taymyr ethnolinguistic paper collection. Volume 1. Data on Nganasan shamanism and language], 190-221. Moscow: RGGU.

Helimski, Eugen. 2007. Materialy k slovarju èneckogo jazyka [Materials for Enets dictionary]. https://www.slm.uni-hamburg.de/ifuu/download/helimski-enzisch.zip.

Himmelmann, Nikolaus. 1998. Documentary and descriptive linguistics, Linguistics 36(1). 161-195.

Janhunen, Juha. 1998. Samoyedic. In Daniel Abondolo (ed.), The Uralic languages, 457-479. London \& New York: Routledge.

Kaufmann, Ingrid. 2007. Middle voice. Lingua 117(10). 1677-1714.

Kazenin, Konstantin I. 2001. Verbal reflexives and the middle voice. In Martin Haspelmath, Ekkehard Konig, Wulf Oesterreicher \& Wolfgang Raible (eds.), Language typology and language universals: An international handbook. Vol. 2, 916-927. Berlin \& New York: de 
Gruyter Mouton.

Kemmer, Suzanne. 1993. The middle voice. Amsterdam: Benjamins.

Khanina, Olesya. 2008. Intransitive split in Tundra Nenets, or how much semantics can hide behind syntactic alignment. In Mark Donohue \& Søren Wichmann (eds.), The typology of semantic alignment, 162-196. Oxford: Oxford University Press.

Khanina, Olesya \& Andrey Shluinsky. 2015. Imperativnye formy v èneckom jazyke [Imperative forms in Enets]. Acta Linguistica Petropolitana 11(2). 610-626.

Kibrik, Aleksandr E. 1997. Beyond subject and object: Toward a comprehensive relational typology. Linguistic Typology 1(3). 279-346.

Klaiman, M. H. 1991. Grammatical voice. Cambridge: Cambridge University Press.

Klimov, Georgij A. 1974. On the character of languages of active typology. Linguistics 131(1). 11-25.

Koval, Antonina I. \& Boureima A. Gnalibouly. 1997. Glagol fula v tipologičeskom osveščenii [Fula verb in cross-linguistic perspective]. Moscow: Russkie slovari.

Kuznecova, Ariadna I., Eugen A. Helimski \& Elena V. Gruškina. 1980. Očerki po sel'kupskomu jazyku. Tazovskij dialect [Essays on Selkup. Taz dialect]. Moscow: Izdatel'stvo Moskovskogo universiteta.

Lazard, Gilbert. 1986. Le type linguistique dit "actif”: réflexions sur une typologie globale. Folia Linguistica 20(1-2). 87-108.

Lyons, John. 1968. Introduction to theoretical linguistics. Cambridge: Cambridge University Press.

Merlan, Francesca. 1985. Split intransitivity: Functional oppositions in intransitive inflection. In Johanna Nichols \& Anthony Woodbury (eds.), Grammar inside and outside the clause, 324-362. Cambridge: Cambridge University Press.

Mikola, Tibor. 2004. Studien zur Geschichte der samojedischen Sprachen. Szeged: SzTE Finnisch-Ugrisches Institut.

Mithun, Marianne. 1991. Active/agentive case marking and its motivations. Language 67(3). 510-546.

Mithun, Marianne. 2014. The data and the examples: Comprehensiveness, accuracy, and sensitivity. In Toshihide Nakayama \& Keren Rice (eds.), The art and practice of grammar writing (Language Documentation \& Conservation Special Publication 8), 25-52. http:// hdl.handle.net/10125/4583 (14. 01. 2019).

Mosel, Ulrike. 2014. Corpus linguistic and documentary approaches in writing a grammar of a previously undescribed language. In Toshihide Nakayama \& Keren Rice (eds.), The art and practice of grammar writing (Language Documentation \& Conservation Special Publication 8), 135-157. http://hdl.handle.net/10125/4589 (14. 01. 2019).

Nikolaeva, Irina. 2014. A grammar of Tundra Nenets. Berlin \& Boston: de Gruyter Mouton.

Prokof'ev, Georgij N. 1937. Ėneckij (enisejsko-samoedskij dialekt) [Enets (Yenisey-Samoyed dialect)]. In Georgij N. Prokof'ev (ed.), Jazyki i pis'mennost' narodov Severa [Languages and written systems of northern peoples]. Vol.1, 75-90. Moscow, Leningrad: Učpedgiz.

Rounds, Carol. 2001. Hungarian: An essential grammar. London \& New York: Routledge.

Salminen, Tapani. 1997. Tundra Nenets inflection. Helsinki: Société Finno-Ougrienne.

Shibatani, Masayoshi. 1985. Passives and related constructions: A prototype analysis. Language 61(4). 821-848.

Shluinsky, Andrey. 2017. Vidovaja sistema èneckogo jazyka na fone russkoj: k tipologii slovoklassificirujuščego vida [Aspect system of Enets against the background of Russian: A case study of "classifying" viewpoint aspect]. Voprosy jazykoznanija 3. 24-52. 
Siegl, Florian. 2011. Aspect in Forest Enets and other Siberian indigenous languages when grammaticography and lexicography meet different metalanguages. In Geoffrey Haig, Nicole Nau, Stefan Schnell \& Claudia Wegener (eds.), Documenting endangered languages: Achievements and perspectives, 121-149. Berlin \& New York: de Gruyter Mouton.

Siegl, Florian. 2013. Materials on Forest Enets, an indigenous language of Northern Siberia. Helsinki: Société Finno-Ougrienne.

Sorokina, Irina P. 1975. Morfologija glagola èneckogo jazyka [Enets verbal morphology]. Leningrad: Leningradskoe otdelenie Instituta Jazykoznanija AN SSSR, doctoral dissertation.

Sorokina, Irina P. 2010. Ėneckij jazyk [Enets]. St. Petersburg: Nauka.

Tatevosov, Sergei G. 2016. Struktura i interpretacija neneckogo glagola: aktantno-akcional'nye klassy i tipy sprjaženija [Structure and interpretation of Nenets verb: actancy-actional classes and conjugation types]. Voprosy jazykoznanija 3. 81-114.

Tereščenko, Natal'ja M. 1966. Ėneckij jazyk [Enets]. In Vasilij E. Lytkin \& Klara E. Majtinskaja (eds.), Jazyki narodov SSSR: Finno-ugorskie i samodijskie yazyki [Languages of the USSR: Fenno-Ugric and Samoyedic languages], 438-457. Moscow: Nauka.

Tereščenko, Natal'ja M. 1967. Vyraženie sub"ektno-ob"ektnyx otnošenij v strukture predloženija (na materiale samodijskix jazykov) [Expression of subject-object relations in the sentence structure (based on the data of Samoyedic languages)]. In Viktor M. Žirmunskij, Solomon D. Kacnel'son, Orest P. Sunik \& I. O. Gecadze (eds.), Ėrgativnaja konstrukcija predloženija v jazykax različnyx tipov [Ergative sentence construction in languages of different types], 289-297. Leningrad: Nauka.

Tereščenko, Natal'ja M. 1979. Nganasanskij jazyk [Nganasan]. Leningrad: Nauka.

Urmančieva, Anna Ju. 2012. Tundra Enets inflectional verbal morphology. Ms., Moscow: Russian Academy of Sciences.

Van Valin, Robert D. 1990. Semantic parameters of split intransitivity. Language 66(2). 221-260.

Verbov, Grigorij D. 1975. Dialekt lesnyx nencev [The dialect of Forest Nenets]. In A. P. Okladnikov et al. (eds.), Samodijskij sbornik [Samoyedic volume], 3-190. Novosibirsk: Institut istorii, filologii i filosofii. 